\title{
Serological Studies of Proteus penneri Strains Determining Qualification to Appropriate O-serogroup
}

\author{
AGATA PALUSIAK*, MAŁGORZATA SIWIŃSKA and ZYGMUNT SIDORCZYK \\ Department of General Microbiology, Institute of Microbiology, Biotechnology and Immunology, \\ University of Łódź, Poland
}

Received 13 September 2012, accepted 31 January 2013

\begin{abstract}
Our Department of General Microbiology created a wide collection of P.penneri isolates and classified most of them into 19 different O-serogroups. This work describes the classification of 12 remaining P. penneri strains. The lipopolysaccharides extracted from P. penneri strains were tested in an enzyme-linked immunosorbent assay (ELISA) with selected O-antisera against Proteus sp. strains. Homologous and cross-reacting systems were checked in: passive immunohemolysis (PIH), inhibition of ELISA and PIH and Western blot procedure. These studies led to the qualification of tested P. penneri strains to five Proteus sp. O-serogroups, thus completing the serological classification of the whole collection.
\end{abstract}

Ke y w ord s: Proteus penneri, lipopolysaccharide, O-serogroup, serological classification

Proteus bacteria are Gram-negative, peritrichously flagellated rods belonging to the Enterobacteriaceae family and capable of swarming growth on solid media. These bacteria are human opportunistic pathogens that in favourable conditions may cause numerous infections, among which the urinary tract infection is the most common (Penner, 1992). Currently, the genus Proteus consists of five named species: P. mirabilis, P. vulgaris, P. penneri, P.hauseri, P. myxofaciens and three species without a specific name P.genomospecies 4, 5 and 6 (O'Hara et al., 2000). The fifth named species of the genus, $P$. myxofaciens, has been recently proposed to be classified into a new genus, Cosenzaea gen. nov. (Giammanco et al., 2011).

Proteus sp. strains have been divided into O-serogroups mainly on the grounds of the serological specificity of the O-polysaccharide part of their lipopolysaccharides. This classification scheme founded by Kauffmann (1966) and Perch included 49 O-serogroups consisting of P. mirabilis and P. vulgaris species only. More O-serogroups were added to this scheme by Penner and Hennessy (1980) (11 O-serogroups) and Larsson et al. (1978) (6 O-serogroups) and they also contained only P. vulgaris and/or P. mirabilis species. The abovementioned scheme was completed also with the third Proteus species, P. penneri - first described and named by Hickman in 1982 (Hickman et al., 1982). A wide and unique collection of these strains has been created in the Department of General Microbiology (University of Łódź, Poland) and comprises 133 P. penneri strains isolated from diverse clinical sources from different sites in the world. The serological and chemical studies of $P$. penneri LPSs have led to classifying 19 P. penneri strains to the existing Proteus $\mathrm{O}$-serogroups and the other 97 P. penneri strains to the new selected O-serogroups consisting of the strains of this species only (Drzewiecka et al., 2004; Knirel et al., 2000; Knirel et al., 2011; Kondakova et al., 2003a, 2003b; Sidorczyk et al., 2002a, 2002b; Shashkov et al., 2000; Zych et al., 2000a, 2000b, 2005a, 2005b). Four of 133 P.penneri strains appeared to be rough forms without the O-polysaccharide part in their LPSs (Sidorczyk and Zych, 1993; Zych and Sidorczyk, 1989). Only one strain from this collection, P. penneri 97 , remained without a defined O-serogroup. Other authors proposed to classify this strain to a new separate Proteus $\mathrm{O}$-serogroup since the antiserum against this strain did not react strongly with any LPSs from strains representing all known Proteus O-serogroups (Drzewiecka et al., 2004). Unfortunately, the antiserum against this strain appeared to contain core-specific antibodies mainly (P.penneri 97 LPS has very short O-polysaccharide chains) and there was no similar LPS to compare with.

To complete the classification of 128 P.penneri strains the next $12 P$. penneri strains were selected for this work.

\footnotetext{
* Corresponding author: Agata Palusiak, Department of General Microbiology, Institute of Microbiology, Biotechnology and Immunology, University of Łódź, Banacha 12/16, 90-237 Łódź, Poland; phone: +48 42-6354469; fax: +48 42-6655818; e-mail: agatapal@biol.uni.lodz.pl
} 
Table I

The strains tested

\begin{tabular}{|c|c|c|}
\hline $\begin{array}{l}\text { The strain } \\
\text { name }\end{array}$ & $\begin{array}{l}\text { The isolation } \\
\text { sources (place) }\end{array}$ & Provided by: \\
\hline P. penneri 3 & urine (Cansas) & \multirow{7}{*}{$\begin{array}{l}\text { Professor D.J. Brenner, } \\
\text { Center for Diseases Control } \\
\text { and Prevention in Atlanta } \\
\text { (USA) }\end{array}$} \\
\hline P. penneri 5 & feces (Texas) & \\
\hline P. penneri 6 & urine (Louisiana) & \\
\hline P. penneri $7^{\star}$ & feces (Missouri) & \\
\hline P. penneri 9 & urine (Georgia) & \\
\hline P. penneri $12^{\star}$ & urine (Alaska) & \\
\hline P. penneri $14^{\star}$ & $\begin{array}{l}\text { bronchial secretion } \\
\text { (Georgia) }\end{array}$ & \\
\hline P. penneri 17 & urine (New Jersey) & \\
\hline P. penneri 23 & unknown (Zurich) & \\
\hline P. penneri $40^{*}$ & unknown (Toronto) & \\
\hline P. penneri $47^{\star}$ & feces (Stockholm) & $\begin{array}{l}\text { Dr. E. Falsen, Department } \\
\text { of Clinical Bacteriology, } \\
\text { Göteborg (Sweden) }\end{array}$ \\
\hline P. penneri 135 & unknown (Paris) & $\begin{array}{l}\text { Dr. G. Giammanco, Institute } \\
\text { of Hygiene and Prevention } \\
\text { Medicine in Catania (Italy) }\end{array}$ \\
\hline
\end{tabular}

* LPSs of these strains were also used as antigens in the work concerning the P.penneri LPS core region (Palusiak et al., 2008). The authors mentioned the O-serogroup numbers of these strains (in the materials and methods section) on the basis of the unpublished partial results of preliminary studies to justify the choice of antigens.

All tested strains (Table I) were collected in the Department of General Microbiology (University of Łódź). P. penneri 12 strain (American Type Culture Collection (ATCC) 33519) is a type strain of P. penneri species (Hickman et al., 1982).

All polyclonal rabbit Proteus sp. O-antisera came from the Department of General Microbiology and they were obtained as described in another article (Sidorczyk et al., 2002c).

The bacteria were grown under aerobic conditions in liquid nutrient broth containing $0.1 \%$ glucose (BTL, Łódź, Poland) at $37^{\circ} \mathrm{C}$. The bacterial masses were harvested after $18 \mathrm{~h}$ of incubation, killed with phenol, centrifuged, washed twice with water and lyophilized in order to obtain dry bacterial cells.

Isolation of the LPSs from lyophilized bacterial cells of smooth strains was performed according to the procedures described in detail elsewhere (Westphal and Jann, 1965).

Alkali-treated LPSs used for PIH and antisera absorption procedures were prepared by saponification of LPSs with $0.25 \mathrm{M} \mathrm{NaOH}\left(2 \mathrm{~h}, 56^{\circ} \mathrm{C}\right)$ and followed by precipitation with ethanol.

All serological assays used in this work including: ELISA, Western blot procedure after sodium dodecyl sulfate (SDS) polyacrylamide gel electrophoresis of LPSs, passive immunohemolysis (PIH), inhibition of ELISA and PIH and absorption of antisera procedure were described in detail elsewhere (Palusiak et al., 2008; Sidorczyk et al., 2002c). In PIH, sheep red blood cells were coated with a maximum concentration of alkalitreated LPSs $(200 \mu \mathrm{g} / 0.2 \mathrm{ml}$ of sheep red blood cells).

The serological characterization of the Proteus penneri $3,5,6,7,9,12,14,17,23,40,47$ and 135 strains is presented. In the preliminary studies the reactivity of all tested LPSs was checked in ELISA with the selective polyclonal rabbit antisera specific to the Proteus sp. strains representing all defined $\mathrm{O}$-serogroups of the genus. Only strong reactions (reciprocal titres ranging from $1: 256.000$ to $1: 1.024 .000$ ) were taken into account. They were observed in four heterologous sets: $P$. penneri 6 and 12 LPSs with the antiserum against $P$. penneri 11 strain (O58); P. penneri 7 and 40 LPSs with P. penneri 52 (O61) and P. penneri 62 (O64 a,b,d) antisera, respectively. LPS of P. penneri 17 reacted with the antiserum against $P$. vulgaris $17 / 57$ (O8) to a lower reciprocal titre $(1: 32.000)$ (Table II). Due to the lack of the sera reactions with the remaining tested LPSs, P. penneri $3,5,9$, $14,23,47$ and 135, it was necessary to examine the possibility of cross-reactions within this group. Thus, an additional serum against P. penneri 14 was obtained and checked with these antigens using ELISA. This strain was chosen since among seven LPSs from this group, only that one has a known chemical structure of LPS O-polysaccharide and may serve as a future standard to which these LPSs can be compared (Vinogradov et al., 1991). The strong cross-reactivity of these systems suggests high degree serological similarities of P. penneri 3, 5, 9, 23, 47 and 135 LPSs to P. penneri 14 LPS (Table II). In order to confirm the obtained results an additional antiserum against one of the tested LPSs cross-reacting with P.penneri 14 antiserum (P.penneri 3 LPS) was selected randomly. This antiserum reacted with $P$.penneri $3,5,9,14,23,47$ and 135 LPSs in ELISA in a way identical to P. penneri 14 antiserum (data not shown).

All homologous and cross-reacting systems were checked in detailed serological studies. In PIH P.penneri 11, 14, 52 and 62 antisera reacted identically with (or similarly to) respective homologous and crossreacting antigens (Table II). The complete abolition of the observed reaction after antisera absorption with cross-reacting antigens confirmed the identity of LPSs within the appropriate tested system. Only in one case the absorption of antiserum was not complete. After antibodies specific to P. penneri 3 LPS were removed from P.penneri $14 \mathrm{O}$-antiserum, immunoglobulins that remained in this antiserum slightly reacted with $P$. penneri 47 LPS (reciprocal titre - $1: 400$ ) (data not shown). This reaction probably concerned the core region of P. penneri 47 LPS, which is serologically similar to but not identical with the core oligosaccharide of P. penneri 14 LPS as has been shown in another article (Palusiak and Sidorczyk, 2009). 
Table II

Serological cross-reactivity of tested P. penneri LPSs with the respective antisera*.

\begin{tabular}{|c|c|c|c|c|c|c|c|c|c|}
\hline \multirow{2}{*}{$\begin{array}{c}\text { Serial } \\
\text { num- } \\
\text { ber }\end{array}$} & \multirow{2}{*}{ 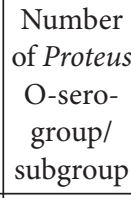 } & \multirow{2}{*}{ Reciprocal titre } & \multirow{2}{*}{$\begin{array}{l}\text { Antiserum } \\
\text { directed } \\
\text { against } \\
\text { strain }\end{array}$} & \multirow{2}{*}{ Tested LPSs } & \multicolumn{2}{|c|}{$\begin{array}{l}\text { Previous contest } \\
\text { of O-serogroup }\end{array}$} & \multicolumn{2}{|c|}{$\begin{array}{c}\text { Minimal inhibitory } \\
\text { dose (ng) }\end{array}$} & \multirow{2}{*}{$\begin{array}{c}\text { Reciprocal } \\
\text { titre for } \\
\text { absorbed } \\
\text { antiserum } \\
\text { in PIH }\end{array}$} \\
\hline & & & & & ELISA & PIH & ELISA & $\mathrm{PIH}$ & \\
\hline 1 & O58 & P. p. 115,125 & P. p. 11 & P. p. 11, 6, 12 & $\begin{array}{l}512.000- \\
1.024 .000 \\
(512.000)\end{array}$ & $\begin{array}{c}25.600- \\
51.200 \\
(25.600)\end{array}$ & $0.5-2(0.5)$ & $0.5-1(0.5)$ & $<100$ \\
\hline 2 & O59 & - & P.p. 14 & $\begin{array}{c}\text { P. p. 14, 3, 5, 9, } \\
23,47,135\end{array}$ & $\begin{array}{c}128.000- \\
256.000 \\
(128.000) \\
\end{array}$ & 12.800 & $1-4(1)$ & $1-4(2)$ & $<100$ \\
\hline 3 & O61 & $\begin{array}{c}\text { P. p. } 21,33,43,50-55,57, \\
58,66-69,72,92,104, \\
109,116,118,127,133,136\end{array}$ & P. p. 52 & $\begin{array}{c}\text { P.p. 52, } \\
7\end{array}$ & 256.000 & 51.200 & $\begin{array}{c}2 \\
16\end{array}$ & $\begin{array}{c}4 \\
16\end{array}$ & $<100$ \\
\hline 4 & O64a,b,d & P.p. 29,39 & P. p. 62 & $\begin{array}{l}\text { P. p. 62, } \\
40\end{array}$ & 256.000 & $\begin{array}{l}25.600 \\
12.800\end{array}$ & $\begin{array}{c}2 \\
62.5\end{array}$ & $\begin{array}{c}2 \\
62.5\end{array}$ & $<100$ \\
\hline 5 & O8 & $\begin{array}{l}\text { P. p. 106, 107, 112, } \\
\text { P. } m \text {. TG326, } \\
\text { P. genomospecies } 5\end{array}$ & P. v. $17 / 57$ & $\begin{array}{l}\text { P. v. 17/57, } \\
\text { P. p. } 17\end{array}$ & $\begin{array}{c}1.024 .000 \\
32.000\end{array}$ & $\begin{array}{l}51.200 \\
6.400\end{array}$ & $\begin{array}{c}8 \\
2.500\end{array}$ & $\begin{array}{c}2 \\
2.500\end{array}$ & $<100$ \\
\hline
\end{tabular}

${ }^{*}$ Respective data for homologous strains, P. p. 11 and 14, are in parenthesis

The results of PIH and ELISA inhibition were consistent for homologous and cross-reacting systems with only one exception: P. penneri 62 LPS inhibited the reaction with the homologous antiserum in a definitely stronger way than P. penneri 40 LPS did (Table II). The Western blot procedure also revealed some differences in both antigens specificity: P. penneri 62 antiserum strongly recognized only the high-molecular-mass species from the homologous strain and weakly reacted with high-molecular-mass LPS of P.penneri 40 strain and low-molecular-mass species of P. penneri 62 LPS (Fig. 1a). In order to find the explanation for the antigenic differences between these two LPSs, another antiserum, directed against P.penneri 40 strain, was added and checked with both LPS preparations in the Western blot technique (Fig. 1b). This time the antiserum reaction with P.penneri 40 LPS referred only to low-molecular-mass species (strong immunoreactivity pattern) whereas the reaction with the other antigen concerned both high- and low-molecular-mass species (weak immunoreactivity pattern). The reasons for differences in serological specificity of both LPSs could be a different length of their O-polysaccharide chains (shorter O-polysaccharides (O-PS) of P.penneri 40 LPS) and a different composition of antibodies in both antisera (a higher level of core-specific antibodies in P. penneri 40 antiserum). Taking into account the above explanation and the outcomes of PIH with the absorbed P. penneri 62 antiserum (Table II), both LPSs: P. penneri 40 and 62 can be regarded as identical and classified into Proteus serogroup O64, subgroup O64 a,b,d.
The other tested antisera, P.penneri 11, 14 and 52 antisera, reacted in the Western blot procedure identically with high-molecular-mass species concerning the $\mathrm{O}$-polysaccharide part of respective homologous and cross-reacting LPSs (Fig. 1c-e). Some differences were observed only for P. penneri 14 antiserum at the level of low-molecular-mass LPS species (Fig. 1d). The immunoreactivity patterns observed for the P. penneri 3 and 14 LPSs were the weakest and the difference between the reactivity of $P$.penneri 47 LPS and the other antigens was the most significant. The classification of Proteus sp. strains into appropriate O-serogroups is based on the serological specificity of the LPSs O-PS mainly, so the small differences in the LPSs core region do not influence this classification.

The last tested antiserum, against $P$. vulgaris $17 / 57$ (O8), exhibited significantly lower reactions with P.penneri 17 LPS as compared with the homologous system in all serological methods (Table II, Fig. 1f). Only the triple absorption of the tested antiserum with P. penneri 17 LPS completely removed all specific antibodies. The final explanation for the serologically different specificity of both antigens (P. penneri 17 and P. vulgaris 17/57 LPSs) was provided by the results of the Western blot procedure. P. vulgaris $17 / 57$ antiserum clearly recognized both low- and high-molecular-mass LPS species from the homologous strain only and slightly bound to low- and high-molecular-mass LPS species of P. penneri 17 strain (Fig. 1f). To make the serological classification more precise P. penneri 17 antiserum was additionally selected. This antiserum strongly reacted only with 

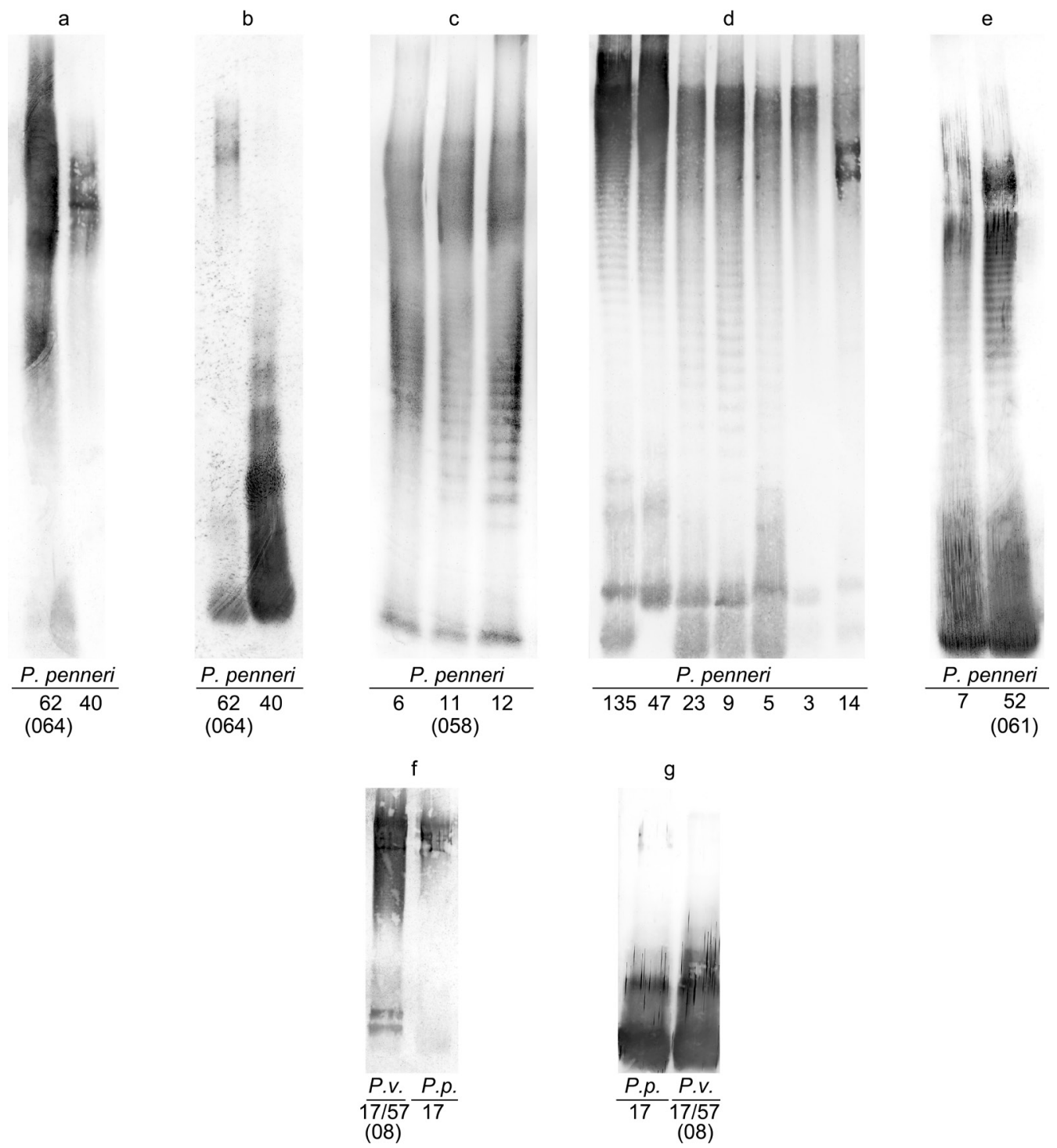

Fig. 1. Western blot of Proteus sp. LPSs with antisera directed against: a P. penneri 62 (O64 a,b,d) strain, b P. penneri 40, c P. penneri 11 (O58) strain, d P. penneri 14 strain, e P. penneri 52 (O61) strain, f P. vulgaris 17/57 (O8), g P. penneri 17

low-molecular-mass LPS species restricted to the core-lipid A moiety of both tested strains (Fig. 1g). It is another example of two antisera of a different antibodies composition: one containing a higher level of core-specific antibodies (P. penneri 17 antiserum) and the other one containing a higher level of O-polysaccharide-specific antibodies (P. vulgaris 17/57 antiserum). Taking into account this observation and the PIH outcomes obtained for the P. vulgaris 17/57 antiserum after its absorption with P. penneri 17 LPS, both strains (P.penneri 17 and P.vulgaris 17/57) can be classified into one common Proteus O-serogroup - O8.

It is worth mentioning that all doubts concerning the results obtained for the tested systems have been resolved after using the absorption procedure, a fundamental method in serological classification.

In conclusion, the results of all serological assays performed have led to a classification of the 12 tested
P.penneri strains into five different Proteus O-serogroups: P. penneri 17 - into serogroup O8, P. penneri 6 and $12-$ O58, P. penneri 3, 5, 9, 14, 23, 47 and 135 - O59, P. penneri 7 - O61 and P.penneri 40 - serogroup O64 (subgroup O64 a,b,d) and allowed completing the serological classification of a unique collection of 128 smooth P. penneri strains collected in the Department of General Microbiology. Seven tested P. penneri strains 3, 5, 9, 14, 23, 47 and 135 formed a new O59 Proteus serogroup and the remaining ones were incorporated into Proteus sp. O-serogroups, which already contained other Proteus strains as shown in table II (Drzewiecka et al., 2004; Kauffmann, 1966; Perepelov et al., 1999; Zych et al., 2000b, 2005c). Only serogroup O8 consists of four different Proteus species and the other four O-serogroups contain P.penneri strains only.

Completing the classification of the collection of 128 smooth P. penneri strains is of high importance for 
the diagnostics of new isolated P. penneri strains since it may serve as a reference scheme according to which new isolates may be serologically classified.

Proteus classification scheme including $78 \mathrm{O}$-serogroups is not closed and new Proteus sp. strains isolated from different materials from patients e.g. in Central Poland are the subject of serological investigation (Drzewiecka et al., 2010). The growing number of multi-drug-resistant strains occurring among P. mirabilis clinical isolates e.g. in Łódź area (unpublished data) necessitates the development of alternative methods of combating or preventing Proteus sp. infections, often persistent and complicated. Using the classification scheme might be a crucial part of Proteus sp. diagnostics. It will also provide information which O-serogroup is prevalent within a certain area. Such data could be also helpful in choosing proper vaccine antigens (LPS) shared by a large number of strains and in obtaining a protective antiserum.

\section{Acknowledgement}

This work was supported by funding for statutory research activity, grant 801 from the Department of General Microbiology, University of Lodz. The assistance of Krystyna Zych is gratefully acknowledged.

\section{Literature}

Drzewiecka D., N.P. Arbatsky and P. Stączek. 2010 Structural and serological studies of the O-polysaccharide of strains from a newly created Proteus O78 serogroup prevalent in Polish patients. FEMS Immunol. Med. Microbiol. 58: 269-276.

Drzewiecka D., K. Zych and Z. Sidorczyk. 2004. Characterization and serological classification of a collection of Proteus penneri clinical strains. Arch. Immunol. Ther. Exp. 52: 121-128.

Giammanco G.M., P.A.D. Grimont, F. Grimont, M. Lefevre, G. Giammanco and S. Pignato. 2011. Phylogenetic analysis of the genera Proteus, Morganella and Providencia by comparison of rpoB gene sequences of type and clinical strains suggests the reclassification of Proteus myxofaciens in a new genus, Cosenzaea gen. nov., as Cosenzaea myxofaciens comb. nov. Int. J. Syst. Evol. Microbiol. 61: $1638-1644$.

Hickman F.W., A.G. Steigerwalt, J.J. Farmer III and D.J. Brenner. 1982. Identification of Proteus penneri sp. nov., formerly known as Proteus vulgaris indole negative or as Proteus vulgaris biogroup 1. J. Clin. Microbiol. 15: 1097-1102.

Kauffmann F. 1966. The bacteriology of Enterobacteriaceae. $3^{\text {nd }}$ ed. The Williams \& Wilkins Co., Baltimore.

Knirel Y.A., A.V. Perepelov, A.N. Kondakova, S.N. Senchenkova, Z. Sidorczyk, A. Rozalski and W. Kaca. 2011. Structure and serology of O-antigens as the basis for classification of Proteus strains. Innate Immunity 17: 70-96.

Knirel Y.A., K. Zych, E.V. Vinogradov, A.S. Shashkov and Z. Sidorczyk. 2000. Structure of a 2-aminoethyl phosphate-containing O-specific polysaccharide of Proteus penneri 8 from a new serogroup O67. Eur. J. Biochem. 267: 815-820.

Kondakova A.N., K. Zych, S.N. Senchenkova, B. Bartodziejska, A.S. Shashkov, Y.A. Knirel, A. Różalski and Z. Sidorczyk. 2003a. Structure of the O-polysaccharide of Proteus penneri 28 and Proteus vulgaris $\mathrm{O} 31$ and classification of P. penneri 26 and in Proteus serogroup O31. FEMS Immunol. Med. Microbiol. 39: 87-93.

Kondakova A.N., K. Zych, S.N. Senchenkova, A. Zabłotni, A.S. Shashkov, Y.A. Knirel and Z. Sidorczyk. 2003b. Structure of the O-polysaccharide leads to classification of Proteus penneri 31 in Proteus serogroup O19. FEMS Immunol. Med. Microbiol. 39: 73-79. Larsson P., H.E. Andersson and B. Norlen. 1978. Serotyping in epidemiological tracing of nosocomially acquired Proteus mirabilis in a geriatric ward. Infection 6: 105-110.

O’Hara C.M., F.W. Brenner and J.M. Miller. 2000. Classification, identification, and clinical significance of Proteus, Providencia, and Morganella. Clin. Microbiol. Rev. 13: 534-546.

Palusiak A., M. Dzieciątkowska and Z. Sidorczyk. 2008. Application of two different kinds of sera against Proteus penneri lipopolysaccharide core region in search of epitopes determining crossreactions with antibodies. Arch. Immunol. Ther. Exp. 56: 135-140. Palusiak A. and Z. Sidorczyk. 2009. Serological characterization of the core regions of lipopolysaccharides of rough Proteus sp. strains. Arch. Immunol. Ther. Exp. 57: 303-310.

Penner J.L. 1992. The genera Proteus, Providencia and Morganella, pp. 2849-2853. In: Balows A., H.G. Trüper, W. Harder and K.H. Schleifer (eds). The Prokaryotes. Springer-Verlag, Berlin, Germany. Penner J.L. and J.N. Hennessy. 1980. Separate O-grouping schemes for serotyping clinical isolates of Proteus mirabilis and Proteus vulgaris. J. Clin. Microbiol. 12: 304-309.

Perepelov A.V., D. Babicka, A.S. Shashkov, N.P. Arbatsky, S.N. Senchenkova, A. Rozalski and Y.A. Knirel. 1999. Structure and cross-reactivity of the $\mathrm{O}$-antigen of Proteus vulgaris O8. Carbohydr. Res. 318: 186-192.

Shashkov A.S., A.N. Kondakova, S.N. Senchenkova, K. Zych, F.V. Toukach, Y.A. Knirel and Z. Sidorczyk. 2000. Structure of 2-aminoethyl phosphate-containing O-specific polysaccharide of Proteus penneri 63 from a new serogroup O68. Eur. J. Biochem. 267: 601-605.

Sidorczyk Z., F.V. Toukach, K. Zych, N.P. Arbatsky, D. Drzewiecka, A. Ziółkowski, S. Shashkov and Y.A. Knirel. 2002a. Structural and serological characterization of the lipopolysaccharide from Proteus penneri 20 and classification of the cross-reacting Proteus penneri strains 10, 16, 18, 20, 32 and 45 in Proteus serogroup O17. Arch. Immun. Ther. Exp. 50: 345-350.

Sidorczyk Z., F.V. Toukach, K. Zych, D. Drzewiecka, N.P. Arbatsky, A.S. Shashkov and Y.A. Knirel. 2002b. Structural and serological relatedness of the O-antigens of Proteus penneri 1 and 4 from a novel Proteus serogroup O72. Eur. J. Biochem. 269: 358-363.

Sidorczyk Z. and K. Zych. 1993. Wybrane właściwości szczepów nowego gatunku Proteus penneri z drugiej kolekcji amerykańskiej. Med. Dośw. Mikrobiol. 45: 69-73.

Sidorczyk Z., K. Zych, F.V. Toukach, N.P. Arbatsky, A. Zablotni, A.S. Shashkov and Y.A. Knirel. 2002c. Structure of the O-polysaccharide and classification of Proteus mirabilis strain G1 in Proteus serogroup O3. Eur. J. Biochem. 269: 1406-1412.

Vinogradov E.V., A.S. Shashkov, Y.A. Knirel and N.K. Kochetkov. 1991. The structure of Proteus penneri 14 O-specific polysaccharide containing D- and L-alanine. Carbohydr. Res. 219: 1-3.

Westphal O. and K. Jann. 1965. Bacterial lipopolysaccharides. Extraction with phenol-water and further applications of the procedure. Methods Carbohydr. Chem. 5: 83-91.

Zych K., N.A. Kocharova, M. Kowalczyk, F.V. Toukach, D. Kaminska, A.S. Shashkov, Y.A. Knirel and Z. Sidorczyk. 2000a. Structure of the O-specific polysaccharide of Proteus penneri 71 and classification of cross-reactive $P$. penneri strains to a new proposed serogroup O64. Eur. J. Biochem. 267: 808-814.

Zych K., M. Kowalczyk, Y.A. Knirel and Z. Sidorczyk. 2000b. New serogroups of the genus Proteus consisting of Proteus penneri strains only, pp 339-344. In: Hacker J., G. Blum-Ochtev, T. Pal and 
L. Emõdy (eds). Genes and proteins underlying microbial urinary tract virulence. Basic aspects and applications. Kluwer Academic/ Plenum Publishers, New York.

Zych K., A.V. Perepelov, A. Baranowska, A. Zabłotni, Y.A. Knirel and Z. Sidorczyk. 2005a. Structure and serological studies of the O-polysaccharide of Proteus penneri 75. Epitopes and subgroups of Proteus serogroup O73. FEMS Immunol. Med. Microbiol. 43: 141-148. Zych K., A.V. Perepelov, A. Baranowska, A. Zabłotni, A.S. Shashkov, Y.A. Knirel and Z. Sidorczyk. 2005b. Structure of the
O-polysaccharide and serological studies of the lipopolysaccharide of Proteus penneri 60 classified into a new Proteus serogroup O70. FEMS Immunol. Med. Microbiol. 43: 351-356.

Zych K., A.V. Perepelov, M. Siwińska, Y.A. Knirel and Z. Sidorczyk. 2005c. Structures of the O-polysaccharides and classification of Proteus genomospecies 4, 5 and 6 into respective Proteus serogroups. FEBS Journal 272: 5536-5543.

Zych K. and Z. Sidorczyk. 1989. Lipopolysaccharides of Proteus penneri species novum. Carbohydr. Res. 188: 105-111. 